\title{
Emergency medicine in Dubai, UAE
}

\author{
Robert Partridge $\cdot$ Michael Abbo • Alamjit Virk
}

Received: 2 February 2009 / Accepted: 6 July 2009 / Published online: 18 August 2009

(C) Springer-Verlag London Ltd 2009

\begin{abstract}
Dubai has rapidly risen to prominence in the Persian Gulf region as a center of global commerce and tourism and as a cultural crossroad between East and West. The health-care infrastructure has undergone rapid development. Collaborations with academic medical centers now exist to advance clinical care, teaching and research. Emergency medicine has also advanced and is undergoing dynamic change. Dubai may soon emerge as a regional leader in emergency medicine training and practice.
\end{abstract}

Keywords Dubai · Emergency department · International · Trauma $\cdot$ Emergency medical services

The views expressed in this paper are those of the author(s) and not those of the editors, editorial board or publisher.

\section{R. Partridge}

Department of Emergency Medicine,

Warren Alpert School of Medicine at Brown University,

Providence, RI, USA

R. Partridge

Division of International Emergency Medicine,

Warren Alpert School of Medicine at Brown University,

Providence, RI, USA

\section{Abbo}

Department of Emergency Medicine,

Rashid Hospital and Trauma Center,

Dubai, UAE

R. Partridge $\cdot$ A. Virk

Department of Emergency Medicine, Emerson Hospital,

Concord, MA, USA

\section{R. Partridge $(\square)$}

Department of Emergency Medicine, Rhode Island Hospital,

593 Eddy Street, Claverick 2,

Providence, RI 02903, USA

e-mail: Robert_Partridge_MD@brown.edu

\section{Introduction}

Dubai is the largest of the seven emirates comprising the United Arab Emirates (UAE) (Fig. 1). Arabic is the official language of Dubai, but English is widely spoken in the medical and business settings, and medical training and practice largely follow a Western model. The development of emergency medicine (EM) is variable across the UAE. Practice in Dubai is advancing rapidly, and the emirate is poised to become a regional leader in EM care.

This report describes the structure of the health-care system in Dubai, with particular emphasis on EM. It examines medical education, the organization of health-care services, emergency department (ED) structure, and the challenges facing EM. Information from Dubai's Department of Health and Medical Services (DOHMS), the Ministry of Health (MOH) for the UAE, hospital visits and physicians practicing emergency medicine in Dubai provided material for this report.

\section{Background}

Dubai's rapid economic expansion began several decades ago with the discovery and export of oil, and has since been further fueled by the emirate's status as a tax-free port. The foundations of its economy are now trade, manufacturing and financial services; only 6\% of Dubai's gross domestic product comes from oil [1]. Tourism has mushroomed, and 10 million visitors are expected annually by 2010 [2]. Emiratis now enjoy one of the highest per capita incomes worldwide [3]. A significant result of Dubai's economic growth is an investment in medicine and improvement in the standard of medical care. As the health-care infrastructure has expanded-including the construction of clinics, 


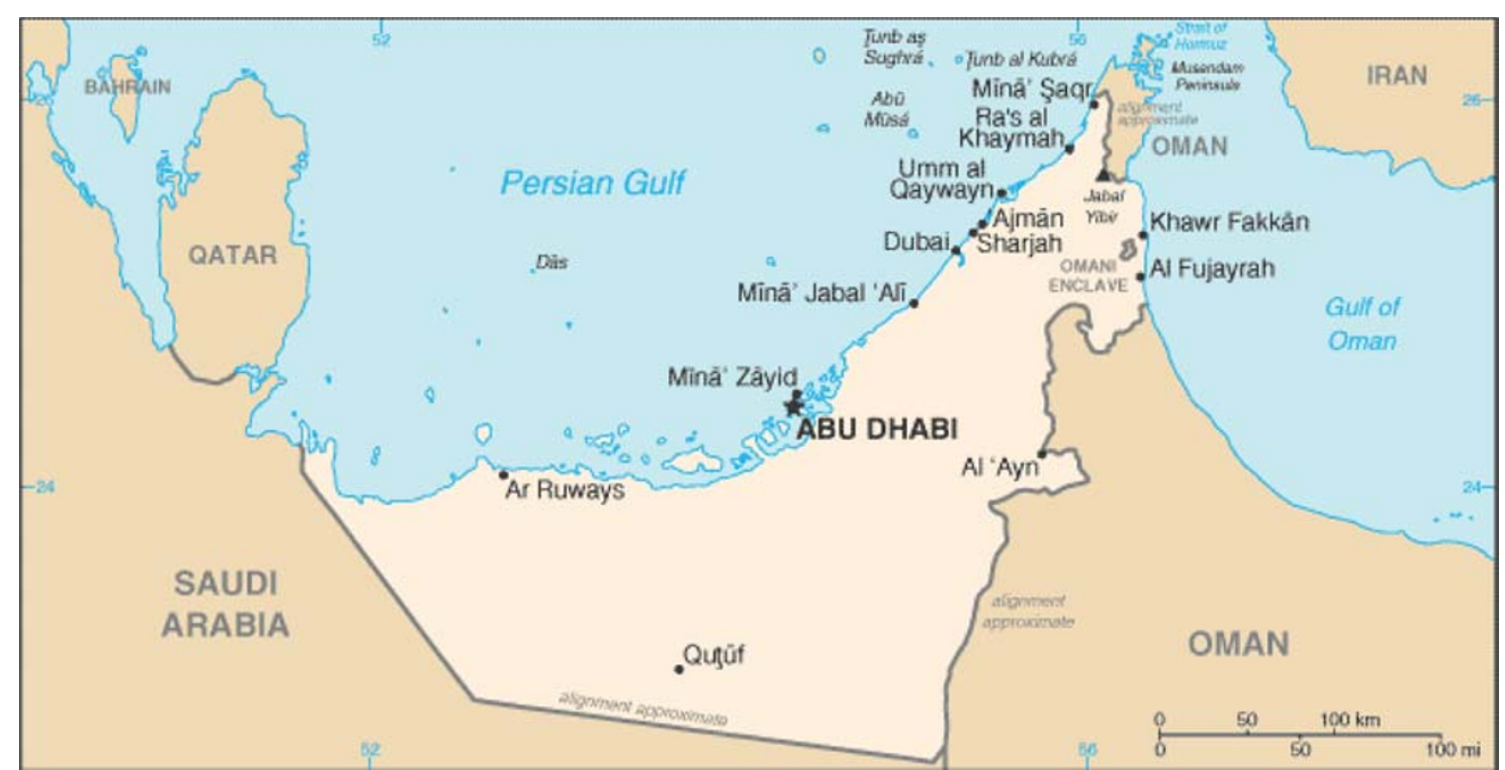

Fig. 1 United Arab Emirates map, showing the location of the Emirate of Dubai. Map from Central Intelligence Agency World Factbook (https:// www.cia.gov/library/publications/the-world-factbook/geos/ae.html)

hospitals, specialized care centers and postgraduate teaching facilities - representation of EM and other medical specialties has also increased [4].

The population of Dubai is estimated to be 1.65 million people, of which $76 \%$ are male [5]. Of the total population, only about $17 \%$ are UAE nationals; most of the remainder are guest workers from India, Pakistan, Bangladesh and the Philippines [6]. Approximately $2 \%$ of the expatriate population originates from Western countries [6]. The median age is 32 years for males and 24.5 years for females [7]. Only $0.6 \%$ of the population is over the age of 65 [7]. Adult literacy is reported to be $77.9 \%$ [3]. The infant mortality rate was estimated at 8.0 deaths per 1,000 live births in 2007 [8].

Health care in Dubai is provided primarily by expatriate physicians from the Middle East, India, Pakistan, Canada and the UK, in addition to some Emirati physicians; nursing staff in hospitals and clinics originate largely from India and the Philippines. Licensure is granted by the Dubai Health Authority (a division of the DOHMS) after demonstration of equivalency training and licensure from the practitioner's home country [9].

EM in Dubai is well developed, with an advanced physical infrastructure, diagnostic equipment and therapies available in most hospitals. Prehospital care is widely available. Two large government-run tertiary care centers, Dubai Hospital and Rashid Hospital, provide all medical and surgical subspecialties. Rashid is also the site of the first postgraduate EM training program in the UAE [10]. Medical and surgical postgraduate training programs exist in both the government hospital system and the private system, and more are planned in the near future [10].
A new multidisciplinary provider of inpatient and outpatient services, Dubai Health Care City (DHCC), is expected to be complete in 2011. DHCC is designed as a regional center of excellence in clinical care, education and research. A private enterprise, DHCC will function without oversight from the DOHMS or MOH. Postgraduate medical education and research programs are affiliated with Harvard University, and dental education and research programs are affiliated with Boston University [11]. When DHCC is complete, it will add 18 specialty hospitals, including a 400bed academic medical center and 2,125 new inpatient beds, to Dubai's medical infrastructure [12]. The academic medical center will include a 36-bed ED, capable of accommodating 50,000 patient visits annually. A hospital-based EMS service is planned at this facility and will provide service cooperatively with the DOHMS ambulance services.

\section{Graduate and postgraduate medical education}

Graduate and postgraduate medical education in the UAE follows the European model. After completion of the US equivalent of high school, students attend medical school for 5 years. The only medical school in Dubai is the Dubai Medical College for Girls, a private institution that accepts 100 students per class [13]. The UAE has three other medical schools, the largest of which is the governmentfunded Emirates University Medical School in Al Ain [1416]. Postgraduate training is available in internal medicine, surgery, obstetrics and gynecology, pediatrics, family medicine, community medicine, psychiatry and emergency medicine. 
The training structure follows the British system, with trainees progressing through senior house officer, registrar, senior registrar, specialist registrar and finally consultant (the equivalent of attending in the US). Training in internal medicine and general surgery is completed over 5 years. Dubai Hospital and Rashid Hospital are the main teaching hospitals. Faculty members monitor clinical performance and have didactic programs similar to those available at teaching hospitals in the United States. British qualification examinations are offered to candidates who have completed training [17].

Dubai has one EM training program for physicians. The inaugural class, consisting of ten residents representing six countries, started their training at Rashid Hospital in July 2008. Among the prerequisites for admission are the completion of a transitional year, an entrance interview and a passing grade in the intern exam administered by the DOHMS. A new residency program in EM is anticipated at DHCC when it opens in 2011. Board examination and certification for qualified candidates are expected through the British Board of Emergency Medicine for graduates of the government program. Dubai is in the process of developing new accreditation standards, which will also apply to EM. The largest EM conference in Dubai is the annual Dubai International Emergency and Catastrophe Management Conference; in addition, the nascent Society of Emergency Medicine holds biannual dinner meetings. Currently, no EM journal is published in the Emirates.

\section{Organization of health-care services}

Dubai is almost entirely urban, and health care is delivered though government and private hospitals, clinics and private medical practices. In 2006, Dubai had 24 hospitals with a total inpatient capacity of more than 2,600 inpatient beds and 200 intensive care beds [12]. Approximately two-thirds of the inpatient beds were at government-funded facilities, under the DOHMS or MOH. Of the nearly 600 outpatient clinics, over $90 \%$ are private [12]. All venues are staffed by physicians and registered nurses; mid-level providers are not recognized by the DOHMS or MOH [9]. The government operates a collaboration of outpatient clinics that take care of the primary health care needs of UAE nationals and guest workers. All except for the most trivial trauma are referred to the Rashid Hospital Trauma Center [9].

Health care is provided free to all citizens of the UAE. Companies that sponsor guest workers are required to provide catastrophic insurance for them. Dubai is in the process of converting to a national insurance plan that would allow individuals to seek acute care in the hospital of their choice. Expatriate workers are repatriated to their home countries for long-term care.

\section{Emergency medical services}

Emergency medical services (EMS) are available throughout the Emirates. Dubai has a centralized EMS system that dispatches 120-150 ambulances per day [18, 19]. Approximately 50-70 inter-hospital ambulance transfers occur daily. The Center of Ambulance Services (COAS) was created in 2006, merging the services of the Dubai police and the DOHMS, the latter of which had previously offered only inter-facility transportation. Call reception and ambulance dispatch are provided by the Dubai police and COAS personnel assigned to police communications. There is a single emergency response activation telephone number, 999. Ambulances are based near hospitals and in several current and emerging population centers. COAS operates approximately 40 ambulances daily, including 2 mobile intensive care units and 6-7 fast-responder units and motorcycles. Four paramedics (a term used to describe all levels of prehospital providers) are assigned to police helicopter duty. Paramedics are also assigned to the communications center, clinics, the airport and to support unit arrival at Rashid and Dubai Hospitals. Ambulances are normally staffed with two paramedics and a driver. The primary work week averages $40+\mathrm{h}$, completed in 8 -h shifts. Most prehospital personnel are expatriate workers.

Fast-responder units (sport utility vehicles) and motorcycles are utilized in heavily congested and high-demand areas to reduce response times. Currently four motorcycles are deployed in the two most congested areas of Dubai and are available $16 \mathrm{~h}$ daily, except during inclement weather and during the hottest months of the year. Fast-responder units typically respond together, which can limit capacity. These units do not typically transport patients, although this does happen during times of system overload (COAS administration, personal communication).

Receiving hospitals for COAS ambulances are primarily Rashid and Dubai Hospitals. Rashid is the designated receiving facility for all trauma patients. Dubai Hospital is the receiving facility for all medical patients except for suspected neurologic, cardiac and gastrointestinal patients, who are transported to Rashid or specialty hospitals. Transport decisions are made in the field using triage protocols, if necessary in consultation with medical control.

Educational and licensing requirements for prehospital personnel are issued by the DOHMS. These standards address equivalency requirements from seven other countries. Continuing education is not required and typically does not occur.

One major system difference between Dubai and Western countries is the absence of a Good Samaritan Law. Although such legislation is in the works, the current lack of protection reduces first-responder intervention. Poor 
penetration of basic life support skills among the general public also significantly limits this component of the EMS system. Another limitation is the lack of education among the public regarding when to activate EMS. Patients with serious conditions such as acute myocardial infarction or stroke are often transported by private car instead of ambulance.

\section{Emergency department organization}

A growing number of hospitals and clinics serve the Dubai population. The systems and equipment necessary to perform the highest level of emergency medical care, including well-equipped and staffed EDs, intensive care units, operating rooms, laboratories, and radiological and other diagnostic services, are widely available. The majority of emergency care is provided at Rashid and Dubai Hospitals. Only a small number of private hospitals provide emergency care and receive ambulance traffic [9]. Private hospitals may have as few as 25 inpatient beds, and not all have EDs. Al Wasl hospital, a DOHMS facility, has a 24/7 ED specializing in pediatric and obstetrical care [9].

Rashid is the largest of the government hospitals in Dubai. It is a 400-bed facility, with an annual ED census of 140,000 patients a year. The hospital provides postgraduate training in medicine and surgery, as well as the new EM program. The ED population is integrated within a single receiving area; approximately $60 \%$ are surgical and $40 \%$ have medical complaints. The average age of the patients reflects the population demographics. Acute traumatic emergencies are common due to the high incidence of industrial injuries, especially to the head and hands. Motor vehicle-related trauma is also common; contributing factors include poor seatbelt compliance and lack of car seat use for children. Approximately 50 patients per day are transferred by ambulance to the ED at Rashid Hospital. The remainder arrive by car, taxi, bus or on foot (Rashid Hospital ED staff, personal communication).

The ED at Rashid is staffed by seven physicians at a time during peak hours. Physicians typically work in 8- or 12-h shifts. Many of these physicians have years of postgraduate training and function independently. Attending physicians with recognized credentials in EM from the US, Canada and the UK supervise during the daytime and are available to consult on difficult cases. One attending physician serves as the Department Head and has administrative responsibility for the ED. If a patient is critically ill, specialists from general surgery, trauma surgery, orthopedics, urology, oromaxillofacial surgery, otolaryngology and neurosurgery can be summoned to the ED 24/7. A dedicated ED anesthesiologist is available 24/7. Patients felt to be in need of emergency surgery are taken immediately to the operating room after stabilization in the ED.

Welcare Hospital, one of the larger private facilities, has 210 inpatient beds and an annual ED census of approximately 72,000 annual visits. No major trauma care is provided. Welcare is a major provider of obstetrical services and averages approximately 160 births/month. Welcare also has its own hospital-based EMS services, staffed by eight paramedics and its own ambulances.

\section{Challenges to emergency medicine}

The development of EM in Dubai is advanced compared with other locations in the Middle East. The standard of emergency care has improved in concert with rapid economic growth. Medical resources, including infrastructure, highly trained physicians and nurses, and an extensive EMS system have all strengthened EM in Dubai. Dubai also has in place a major disaster contingency plan that encompasses DOHMS, MOH, government and private hospitals, and EMS [20].

Although the practice of EM is advanced, the coordination and standardization of efforts among the various private, governmental and teaching hospitals is limited. Such coordination is likely to improve through the development of postgraduate training programs in the near future. State-ofthe art teaching facilities, including a medical simulation center, are expected to be complete within the next 3 years. In addition, continuing medical education programs and a board certification process in EM have been initiated, and linkages with foreign universities with strong EM programs have been established.

It the future, the development of a regional or national program for accreditation in EM will be important. A recognized professional organization dedicated to EM will serve to strengthen the specialty and coordinated and standardized emergency care throughout Dubai, and eventually throughout the UAE.

Another major challenge for EM in Dubai is rapid expansion of the population, which is expected to double to 3.4 million by 2015 [10]. This challenge is being addressed through the construction of the DHCC and other private hospitals. When completed, these facilities will provide more than 3,400 additional inpatient beds and will shift the majority of inpatient beds from the public to the private sector [12].

The organization of EM training and practice also presents challenges. Physicians with ED experience staff most EDs. However, board certified or board eligible (BC/ $\mathrm{BE})$ emergency physicians are lacking. This results in ED supervision by $\mathrm{BC} / \mathrm{BE}$ emergency physicians occurring only during the busiest parts of the day; at other times, $\mathrm{BC} /$ $\mathrm{BE}$ coverage is through telephone consultation. Fellowship training in EM subspecialties is not currently planned. 
However, the completion of the academic medical center at DHCC will present an opportunity to develop EM teaching and research. Community intervention, especially in the discipline of injury control, will also be paramount. Establishing a trauma systems registry will be required to improve the overall delivery of trauma care.

As Dubai continues to expand economically, provision of emergency medical care will likely begin to match more closely emergency care as practiced in Western countries. Dubai may soon have one of the most advanced systems of emergency care in the Middle East, which will be a model for other emirates in the UAE and other regional countries to follow.

\section{Conflicts of interest None.}

\section{References}

1. Dubai Chamber of Commerce. Dubai Macroeconomic Report: Multi-Sectoral Approach. Available from: http://web2.dubaichamber. ae/pdf/reports/Dubai-Macroeconomic-Report.pdf. Accessed May 7, 2009

2. Bowman D. Arabian Business.com. Available from: http://www. arabianbusiness.com/518541-dubai-tourist-numbers-set-to-hit$10 \mathrm{mn} ? \mathrm{ln}=\mathrm{en}$ Accessed May 7, 2009

3. CIA-The World Factbook. United Arab Emirates. Available from: https://www.cia.gov/library/publications/the-world-factbook/geos/ae.html. Accessed May 7, 2009

4. Blesch G (2007) Rising in the Persian Gulf. Dubai and other United Arab Emirates states are using US know-how to build a cutting edge healthcare infrastructure. Mod Healthc 37(31):26-28

5. Government of Dubai. Dubai Statistics Center. Available from: http:// dsc.gov.ae/DSC/uploads/SharedDocuments/Dubai_in_Figures_2304-09.pdf. Accessed May 7, 2009

6. Globalization, Urbanization, Migration. MPI Data Hub. Available from: http://www.migrationinformation.org/dataHub/GCMM/ Dubaidatasheet.pdf. Accessed May 7, 2009

7. Government of Dubai. Dubai Statistics Center. Available from: http://www.dsc.gov.ae/DSC/uploads/SharedDocuments/Gender statistics_2007.pdf. Accessed May 7, 2009

8. Government of Dubai. Dubai Statistics Center. Population and Vital Statistics. Available From: http://www.dsc.gov.ae/DSC/ webreports/590755332OSI01-13.pdf. Accessed May 7, 2009

9. Government of Dubai. Department of Health and Medical Services. Available from: http://www.dohms.gov.ae. Accessed May 7, 2009

10. Government of Dubai. Department of Health and Medical Services. Available from: http://www.dohms.gov.ae/NewsEvents/Events/Specialties.htm. Accessed May 7, 2009

11. Dubai Health Care City. Available from: http://www.dhcc.ae Accessed May 7, 2009
12. Government of Dubai. Center for Healthcare Planning and Quality. Available from: http://edohms.dohms.gov.ae/mpt/ form_files/HealthCare_and_Population_Statistics.pdf. Accessed May 7, 2009

13. Dubai Medical College for Girls. Available from: http://www. dmcg.edu/. Accessed May 7, 2009

14. United Arab Emirates University. Available from: http://www. uaeu.ac.ae/colleges/. Accessed May 7, 2009

15. World Health Organization. Available from: http://www.who.int/hrh/ wdms/media/en/United Arab Emirates.pdf. Accessed May 7, 2009

16. University of Sharjah. Available from: https:/www.sharjah.ac.ae/ English/Academics/Pages/DegreesandPrograms.aspx Accessed May 7, 2009

17. Government of Dubai. Department of Health and Medical Services. Available from: http://www.dohms.gov.ae/NR/rdonlyres/ 1C56A7BD-09CB-4847-9A8F-E10A8C4012C9/706/OVERVIE WOFTHEDUBAIRESIDENCYTRAININGPROGRAMME1.pdf. Accessed May 7, 2009

18. Gupta K. Dubai Ambulance: working to save our lives. Gulf News. Available at: http:/www.xpress4me.com/news/uae/ dubai/20008984.html. Accessed May 7, 2009

19. Government of Dubai. Center of Ambulance Services. Available at: http://www.ambulance.gov.ae/index.php?option=com content\& task=view\&id=2\&Itemid=9\&lang=english. Accessed May 7, 2009

20. Muslim N (2009) Dubai working on disaster management plan for ports. Gulf News. Available at: http://www.gulfnews.com/Nation/ General/10204312.html. Accessed May 7

Robert Partridge, MD, MPH practices emergency medicine in both the clincial and academic setting, and is an Associate Professor at the Warren Alpert School of Medicine at Brown University. $\mathrm{He}$ is a specialist in international health and has 20 years of experience working and teaching in emergency medicine throughout the world. He has participated in several international disaster relief operations. Dr. Partridge received his Bachelor of Science and Medical Degree from Tufts University and his Masters in Public Health from Harvard University. His interests are in international emergency medicine, injury and disease prevention, and geriatrics. Dr. Partridge serves as a Board Examiner for the American Board of Emergency Medicine and as the American College of Emergency Physicians ambassador to Cuba.

Michael Abbo, MD, MEd is an American board certified residency trained emergency medicine physician currently working as a consultant at Rashid Hospital Trauma Center in Dubai, UAE. He also serves as emergency medicine residency director at the same institution. He has a major interest in medical education and has organized and participated in several major emergency medicine and disaster conferences in the middle east.

Alamjit Virk, MD, MPH is an emergency physician based in Boston, MA. His primary interests are in emergency medicine administration and public health. He has served as a consultant advisor on a variety of projects in international health. 